\title{
Uma Enciclopédia Amazônica
}

\author{
Antonio Porro*
}

Tesouro Descoberto no Máximo Rio Amazonas, Pe. João Daniel, Rio de Janeiro, Contraponto / Belém, Prefeitura Municipal, 2004. 2 vols.

São as riquezas do rio Amazonas e o tesouro de que falo, a grande fertilidade das suas terras, as preciosas especiarias das suas matas e as copiosas colheitas dos seus frutos, porque nos frutos da terra e bens estáveis consiste a mais estimável riqueza dos homens, e não nos ouros, pratas e preciosas gemas, que de repente se podem perder e desaparecer em um momento ...

Eu bem sei que exponho a muitas censuras esta obra, pelo que contém de novo e desusado aos que já estão habituados no antigo cultivo daquelas terras, porque sempre as novidades causarão admiração aos antigos ... [e porque] só os que têm cópia de escravos que thes façam o serviço dos roçados blasonam e se chamam ricos, ainda que a maior parte deles perdendo [agora] os escravos pela justíssima lei das liberdades promulgada no ano de 57, em que se declaram libertos todos os indios ...

Não pretendo dar regras a quem as não quer tomar; ... o meu intento é só insinuar, aos povoadores que de novo vão concorrendo e a todos os que não têm escravos nem acham jornaleiros (porque na verdade os não há nas conquistas, por se venderem e blasonarem de fidalgos todos os que lá chegam, embora que na Europa e na sua pátria fossem mochilas, lacaios ou mariolas), um meio mais útil, fácil e acomodado para principiarem a sua vida.

Bastam esssas poucas frases, pinçadas ao longo de uma obra monumental e ainda pouco lida, para atestar que o grande livro do jesuíta João Daniel, além de ser, nas palavras de José Honório Rodrigues, a "mais importante fonte para o estudo do Amazonas no século XVIII ... uma obra enciclopédica, um tratado, um tesouro de todo o Amazonas", é também o produto singular de uma aguçada sensibilidade

* Antonio Porro é doutor em antropologia pela Universidade de São Paulo e especialista em etno-história da Mesoamérica e da região amazônica. Desenvolve atualmente pós-doutorado junto ao IEB e é autor, entre outras obras, de $O$ messianismo maya no período colonial, As crônicas do rio Amazonas e $O$ povo das águas. 
e de atentas reflexões sobre os problemas sociais e econômicos da colônia, traço incomum na literatura setecentista da região, que o colocam em lugar de destaque na história da cultura luso-brasileira.

A biografia e a obra do autor foram estudadas por Serafim Leite ${ }^{1}$ e por José Honório Rodrigues ${ }^{2}$. João Daniel, diz o seu registro no cárcere do Forte de Almeida, nascera em Travaçós, diocese de Viseu, a 24 de julho de 1722, filho de Manuel Francisco Canario e de Maria, "de que se não sabe o sobrenome"; Serafim Leite sugere que seria Maria Daniel, posto que era costume dos jesuitas usar o sobrenome materno quando o do pai, por insólito, "parecesse menos grave" (1942, pp. 79-80). Ainda conforme o historiador da ordem,

João Daniel entrou na Companhia, em Lisboa, dia 17 de dezembro de 1739; e dois anos depois, com menos de vinte, embarcou para o Estado do Maranhão e Grão Pará. Estudou Humanidades (3 anos) e Filosofia no Colégio Máximo de S.Luiz. Em 1747 era aluno distinto de Física, estudando ao mesmo tempo Teologia ... Ordenou-se sacerdote este mesmo ano [1750] ou princípio do seguinte, dado que neste de 1751 se apresenta já como Padre, entregue a ministérios sobretudo no Pará, percorrendo Aldeias e Fazendas ... [Anos depois], já em plena batalha e enquanto esperava o exílio, emitiu a profissão solene de quatro votos a 20 de novembro de 1757. (op. cit., p. 80)

É só isto, praticamente, o que se sabe da vida de João Daniel até a sua expulsão de Belém . Havia sido proficiente em Física, matéria anual que, depois da Lógica e antes da Metafísica, compunha o triênio de estudos de Filosofia, e nela devem ter-se fundamentado tanto a sua capacidade de sistematizar as coisas da natureza, como a racionalidade do seu juízo crítico. Fôra preparado para ser o cronista da sua Vice-Província e instrumentos para isso os tinha, visto que nos colégios do Maranhão e Grão Pará as bibliotecas jesuíticas já reuniam mais de 12.000 livros. Ao mesmo tempo, porém, observa Serafim Leite, João Daniel era dotado "daquele decidido criticismo com que os missionários da América ... temperaram as prepotências ou os abusos dos grandes do mundo". E teria sido a pretexto de um seu sermão de sexta-feira santa, quando investira pouco vela-

1 Leite, Serafim. “João Daniel, autor do 'Tesouro descoberto no máximo rio Amazonas". Revista da Academia Brasileira de Letras, Rio de Janeiro, Vol. 63, 1942, pp. 79-87. E na História da Companhia de Jesus no Brasil. Rio de Janeiro, Imprensa Nacional, Vol. IV, 1943 ; pp. 325-9 e Vol. VIII, 1949, pp.190-2.

2 Rodrigues, José Honório. História da História do Brasil. $1^{a}$. parte: Historiografia Colonial. São Paulo, Ed. Nacional / Brasília, INL, 1979 (“Brasiliana” Grande Formato, 21), pp.95-100. 
damente contra os repetidos ataques que o governador Mendonça Furtado e o bispo D. Miguel de Bulhões faziam aos jesuitas ("Anás e Caifás faziam a sua vontade e os apóstolos de Cristo estavam a dormir"), que João Daniel foi, entre os jesuitas desterrados, um dos poucos a sofrer o castigo mais rigoroso: a prisão perpétua (op. cit., pp. 80-81).

Banido da colônia ao final de 1757, João Daniel passou os primeiros quatro anos de cativeiro no Forte de Almeida, em condições de extremo rigor. Por crueldade, sabendo que o que lhe restava era escrever, mas também por precaução, pois tentara dirigir uma petição ao rei, eram negados, a ele e a seus companheiros, papel e tinta para escrever. As condições adversas do seu longo cativeiro levaram mais de um autor a se perguntar como poderia João Daniel, na masmorra em que passou os seus últimos dezoito anos e privado de suas fontes e até mesmo de papel para escrever, ter produzido obra tão extensa e documentada. Foi sugerido que a obra teria sido escrita ainda no Pará ${ }^{3}$, mas isso é desmentido pelo seu zeloso carcereiro, Manuel Freire de Andrade, comandante da Praça do Forte de Almeida, que em ofício a Sebastião José comprazia-se em relatar que havia sequestrado aos prisioneiros todos os papéis que traziam consigo: "Como lhes falta o papel, porque nem para as fontes lho consinto há muito tempo ... Mandei-lhes entregar os Breviários para continuarem as rezas, arrancando-lhes primeiro todas as folhas brancas, e tirando-lhes alguns registos, porque nas costas de dous tinha o Padre João Daniel feito duas petições para Sua Majestade, que Vossa Excelência verá, por irem inclusos nos papéis pertencentes ao dito Padre" (op . cit. p. 82). Que a obra, de fato, tenha sido redigida de memória, sem o apoio de anotações prévias, é sugerido pelas muitas lacunas do texto quando o autor, narrando ocorrências específicas, deixa em branco nomes próprios, datas ou distâncias.

Em fevereiro de 1762 João Daniel foi transferido para a Torre de S.Julião da Barra, onde estavam relegados os padres considerados "grandes criminosos". Lá, por outro lado, a disciplina foi menos rigorosa e deve ter recebido o papel e a tinta com que, no decorrer dos cinco anos seguintes, escreveu o seu Tesouro, como ele mesmo diz, para lhe servir "de honesto divertimento em tanta miséria". Distribuídos de dois em dois ou de três em três em cada uma das 28 celas de S.Julião, os condenados trocavam recordações e certamente depoimentos; alguns, pela idade e pela experiência, conheciam a Amazônia muito mais do que o próprio João Daniel :

3 Papavero, Nelson. "Relíquia do século 18". Ciência Hoje, Vol. 35, 2004, n. 208, p. 77. 
“Um missionário que viveu e missionou quase toda a sua vida nas missões daquele rio, donde veio com os mais a morrer nestas catacumbas, lendo este meu parecer (além de outros) me confessou que ... não havia outro meio, nem mais proporcionado nem mais fácil, do que este que aponto. 0 mesmo me [as]segurou outro, ... que além da prática que teve muitos anos daquelas terras, tem a lição de todos os historiadores que as têm descrito, e muitas outras noticias particulares que quer deixar aos vindouros em um curioso tomo que intitulou Atlas americano, o qual fazendo-me a graça de também me dar nestes escritos o seu parecer, o expressou nestas poucas palavras: V.R. guarde estes papéis, porque o seu parecer em quase tudo se conforma com o meu juizo, etc. etc. etc.” (Parte Quinta, Introdução).

Outra circunstância a indicar que o isolamento carcerário do autor acabou sendo atenuado, é o fato de que em 1767 ele pôde remeter a Sexta Parte do seu manuscrito, bem como uma versão abreviada da Quinta, ao seu sobrinho Frei Gregório José Viegas, que com elas presenteou o seu mestre Frei Manoel do Cenáculo Vilas Boas, bispo de Évora, que as incorporou à biblioteca local (Anônimo, provavelmente Azeredo Coutinho, Advertência à edição de 1820 do Tesouro; Wilson Lousada, Nota Explicativa à edição de 1976). A ser correta a data daquela remessa, 1767 é o terminus ante quem da redação do Tesouro.

João Daniel faleceu na prisão, aos 53 anos de idade, em 19 de janeiro de 1776, um ano antes da queda de Pombal e da anistia de D. Maria I aos presos políticos. Foi sepultado na igreja de S. Julião da Barra.

\section{Tesouro descoberto no máximo rio Amazonas} compõe-se de seis partes, algumas delas publicadas individualmente ainda no século XIX; a primeira edição integral sò viria à luz em 1976:

Quinta Parte do Thesouro Descoberto no Rio Amazonas. Rio de Janeiro, Impressão Régia, 1820, 151 pp. Esta edição baseou-se em 'fiel cópia' do manuscrito da quinta parte existente na biblioteca de Évora (vide adiante).

"Parte Segunda do Tesouro Descoberto no Rio Amazonas”. Rev. Inst. Hist. Geogr. Bras., Rio de Janeiro, Vol. 2 (1840), 2a . ed., 1856, Vol. 2, pp. 321-364, 447-500; Vol. 3, pp 39-52, 158-183, 282-297, 422-444.

"Parte Sexta do Thesouro descuberto no Rio Máximo Amazonas”. Rev. Inst. Hist. Geogr. Bras., Vol. 41 (I), 1878, pp.33-142. Também reproduz manuscrito de Évora. 
Tesouro descoberto no rio Amazonas. Separata dos Anais da Biblioteca Nacional, v. 95, t. 1-2, 1975. Rio, 1976, $437+440$ pp. 0 manuscrito das partes 1 a 5, de 766 páginas, pertencia à Real Biblioteca de Lisboa; veio para o Brasil com a família real em 1808 e está agora na Biblioteca Nacional do Rio de Janeiro. Na biblioteca de Évora existe outra versão, diferente e muito mais reduzida, da $5^{\text {a }}$. parte, bem como uma $6^{a}$. parte inexistente no códice da Biblioteca Nacional, que as recebeu em microfilme e que integram esta edição.

A Primeira Parte, sem título, mas que costuma ser designada pelo do seu primeiro capítulo ("Descrição geográfico-histórica do rio Amazonas"), trata na verdade da hidrografia (capítulos 1 a 13), dos peixes e anfíbios (14 a 16), das aves (17-18), dos mamíferos (19 a 21), dos insetos (22 a 27) e das cobras e antídotos para seus venenos (28-29).

A Segunda Parte, "Notícia geral dos índios seus naturais e de algumas nações em particular, etc.", trata genericamente da sua aparência, caráter, crenças, costumes, aptidões, guerra e antropofagia (capítulos 1 a 15); diz alguma coisa dos Incas e dos Maina do alto Amazonas peruano e passa a tratar mais em particular dos Cambeba do Solimões, dos Uriquena do rio Negro, dos Purus do rio homônimo, dos Mura deste e do Madeira, dos Torases e Urupases do Madeira, dos Arapium, Gurupá e Jaguaim do Tapajós, dos Juruna, Acipóias e Carnises do Xingu, dos Maraguás do Cumá, dos Tupinambá do litoral, dos Tupinambarana do médio Amazonas, dos Nheengaiba e Mamainases da foz do Amazonas, dos Pacajás do rio homônimo, dos Cabaços e dos Gamelas do Maranhão, dos Canoeiros do Tocantins, e finalmente dos Goianases, Iranambés e Barbados, não localizados (capítulos 16 a 19); trata a seguir da condição física e doenças dos índios (20) e conclui com uma descrição de Belém e das vilas e povoados do interior, até o baixo Madeira (21).

A Terceira Parte "Dá notícia da sua muita riqueza nas suas minas, nos seus muitos e preciosos haveres e na muita fertilidade das suas margens" e se compõe de seis tratados: $1^{\circ}$. Das minas de ouro e prata e diamantes, anunciado como "compendiosa notícia dos seus muitos e inexauríveis minerais", mas que se resume às duas páginas iniciais, visto faltar todo o restante (três ou quatro capítulos) no manuscrito da Biblioteca Nacional e, consequentemente, na edição integral de 1976 e na de 2004 aquí resenhada. $2^{\circ}$, do qual, pela mesma razão, falta o enunciado e parte do primeiro capítulo e que, portanto, nas duas edições, vem constituir equivocadamente os capítulos 2 a 8 do $1^{\circ}$. Tratado; versa sobre as plantas silvestres e cultivadas. $3^{\circ}$. Da riqueza do Amazonas 
na preciosidade da sua madeira, trata, em seis capítulos, das árvores, arbustos e ervas úteis. $4^{\circ}$. Das palmeiras da América (capítulo único). $5^{\circ}$. Do principal tesouro do rio Amazonas, que em sete capítulos trata dos produtos naturais e beneficiados de origem vegetal, animal e mineral. $6^{\circ}$. Das tintas mais especiais do rio Amazonas (dois capítulos).

A Quarta Parte, sem título e com treze capítulos, é uma descrição analítica da economia amazônica: agricultura, engenhos de açúcar, embarcações, missões religiosas, viagens ao sertão para coleta de drogas, pecuária, pesca, comércio e olaria.

A Quinta Parte, "Em que se mostra um novo e fácil método da sua agricultura ... povoação e comércio", faz contraponto à quarta, arrolando em oito tratados inúmeras sugestões para se obterem melhores resultados econômicos com justiça e boa ordem social: $1^{\circ}$. na agricultura, com o abandono do onipresente e ineficiente cultivo da mandioca e a adoção de trigo, milho e outros cereais; $2^{\circ}$. na navegação, que deveria ficar a cargo de transportadores profissionais; $3^{\circ}$. na horticultura, que deveria substituir o extrativismo predatório e dispendioso; $4^{\circ}$. na construção de embarcações, com o abandono da tradicional canôa indígena e a introdução de barcos de pranchas; $5^{\circ}$. na pesca; $6^{\circ}$. nas missões religiosas, que propõe fortalecer mas também livrar de velhos vícios; $7^{\circ}$. no povoamento da região, com liberdade para os índios e incremento planejado da imigração européia e, $8^{\circ}$. nas técnicas de conservação e beneficiamento das colheitas.

Segue-se, com título semelhante mas reduzida a menos que a metade da extensão, a Quinta Parte na versão do manuscrito de Évora acima referido.

A Sexta Parte, em catorze capítulos, "Contém inventos úteis e curiosos para a melhor navegação, fazendo prósperos todos os ventos, ainda os mais ponteiros e contrários, e para fazer nas calmarias boa viagem. Com nova invenção de represar as marés para mo[v]erem fábricas e engenhos de moto contínuo. Acrescem algumas outras idéias de engenhos manuais para serrar madeira, fazer açúcar, e muitos outros não menos curiosos que úteis à vida humana".

Não deve surpreender que uma obra de tal magnitude, versando sobre temas tão variados e escrita em condições tão penosas, seja de qualidade e valor desigual. Até certo ponto, a própria matéria condiciona o discurso e o estilo; as três primeiras partes (que nesta nova edição correspondem ao Vol. I), são essencialmente descritivas e percebe- 
se nelas maior ou menor familiaridade com os assuntos, diferentes graus de objetividade e até um inesperado senso de humor. A seção de peixes e anfíbios abre-se com um esclarecimento: "Não pretendo aquí descrever toda a variedade de peixe ... mas só descrever os mais principais e menos conhecidos na Europa ou que excedem no mimoso"; asseverando este propósito, o primeiro gênero a integrar aquela família é o do homem marinho, em que entram sereias e seres humanos que teriam-se mudado para o fundo dos rios; seguem-se, pela ordem, jacarés, lagartos, camaleões, tartarugas, lontras e tatus. Mais adiante, o primeiro dos mamiferos a ser apresentado é a anta, que "tem a grandeza de um grande jumento ... mas parece [que] não é tão asno como o burro, porque a ninguém dá ancas [i.e., não se deixa cavalgar]" e que "talvez mereça os primeiros méritos pelo seu delicioso gosto nos banquetes". Pouco decoro no estilo, como entendeu Varnhagen ${ }^{4}$ referindo-se talvez a passagens como esta, ou sadia higiene mental para tentar sobreviver em tanta miséria?

Mas este lado imaginoso (a sentença é de Euclides da Cunha $^{5}$ ) de João Daniel restringe-se a uma minoria de temas que ele, provavelmente, impusera-se abordar para construir o seu quadro da natureza, mas que devia julgar mais de entretenimento e ilustração do que propriamente dignos de mais detidas considerações. De fato, em temas que tocam mais de perto as necessidades e o cotidiano da população colonial e dos índios aldeados, o superficial, a crendice e o chiste dão lugar, via de regra, à exposição organizada e meticulosa do mundo natural e das suas possibilidades de aproveitamento econômico. É assim para os peixes, aves, plantas, madeiras e essências nativas mais importantes para a alimentação, a indumentária, o abrigo, a navegação e a medicina popular da Amazônia. É assim nos seis capítulos em que esmiuça o mundo dos insetos, vermes, aracnídeos e outras pragas pestilentes que atormentam e debilitam a saúde humana e animal. E é assim na longa e minuciosa descrição geográfica da bacia do Tocantins (o mais importante caminho de Belém para as minas de Goiás e o centrosul do Brasil), ordenada em 61 parágrafos que remetiam a outros tantos pontos assinalados num mapa que acompanhava o Tesouro, e que se perdeu. Em relação à natureza e aos direitos dos índios, o seu julgamento não é livre de ambiguidades: de um lado, afirma que "só pelas feições pa-

4 Varnhagen, Francisco Adolfo de. História Geral do Brasil. 6a. ed.. São Paulo, Melhoramentos, 1959, vol. IV, p.143..

5 Cunha, Euclides da. Contrastes e confrontos. Porto, 1907. 
recem gente, [mas] no viver e trabalhar se devem entender por feras ... exceto os poucos que já pela notícia e comunicação dos europeus, e pelas contínuas lições dos missionários se têm feito homens e cristãos"; de outro, ao criticar os que justificam a servidão dos índios por serem "rústicos", pergunta-se: "mas quem dirá que, por ser rústico, um português se [submeta], nas suas mesmas terras, a trabalhar e servir a qualquer estranho que nelas se meta?"

Não obstante as muitas repetições em que incorre, a arquitetura geral da obra está sempre clara na mente do autor. Tendo-se desincumbido das partes descritivas "com rústicas expressões suficientes a formar nos leitores algum conceito do seu descoberto tesouro", ele se propõe, na Quarta parte, a "dar a desejada notícia da maestria e indústria com que os seus naturais, índios e europeus, se utilizam dos seus haveres" e, na Quinta, a "mostrar o modo de se poderem extrair essas riquezas ... com [o] qual não só se não perderão os novos colonos, mas se saberão utilizar para viver com fartura e para enriquecer com brevidade". E aquí se revela, já mais livre da retórica barroca, do pedantismo de ofício e das ocasionais frivolidades, o melhor de João Daniel. Na Quarta parte é o observador atento e bom conhecedor das técnicas extrativistas, da pecuária e da agro-indústria; dos pontos nodais da produção, transporte e distribuição da mercadoria; da dupla função, material e espiritual, da missão religiosa em seus papéis inevitavelmente contraditórios dentro da ordem colonial. E na Quinta, verdadeira peça de resistência do Tesouro, como também na Sexta, é o criativo, polêmico, por vezes ingênuo mas sempre generoso reformador da economia e da sociedade, esperançoso de um futuro melhor para o país que adotou e que perdeu:

"Falo, propriamente, com os novos povoadores que da Europa, onde vivem uma vida pobre, laboriosa e miserável, vão concorrendo a buscar naquelas terras o seu remédio, de que se vão povoando cada vez mais aqueles estados, que em algum tempo virá a ser o mais rico e invejado do mundo; com estes, pois, fala o meu método e direções, porque sem elas pasmam os novos colonos quando se vêem naquela vastidão de terras incultas, à vista de matas inacessiveis, sem mais cultura que a da natureza e sem mais benefício que o da terra; e desanimados se encolhem os braços e se atam as mãos, sem tomar outra resolução mais do que dar-se a uma calaçaria, porque lhes parece impossivel o poder cultivar sem o adjutório de muitos operários, que não têm ..."

É impossível, diante de tais declarações de princípios, não fazer um paralelo entre o Tesouro de João Daniel e Cul- 
tura e Opulência do Brasil, de Antonil ${ }^{6}$ (s.d. [1711]), obra que o precedeu nos primeiros anos do século XVIII. Podese dizer que, afora o fato das duas obras tratarem da economia colonial e de seus autores serem jesuitas, nada mais elas têm em comum. São diferentes no alcance (naturalista e enciclopédico um, técnico-econômico o outro) e no âmbito sócio-geográfico (periférico e despovoado um, dinâmico e concentrador de riqueza o outro), mas acima de tudo no enfoque, na postura e no propósito. João Daniel analisa o sistema, diagnostica os seus males e propõe soluções alternativas para promover o progresso econômico e com isso beneficiar "os novos povoadores que ... vivem uma vida pobre, laboriosa e miserável". Antonil, muito mais competente e exaustivo na descrição do processo econômico, erige e dedica o seu monumento "aos que, nos engenhos do açúcar, nos partidos e nas lavouras de tabaco, e nas minas do ouro, experimentam o favor do céu com notável aumento dos bens temporais". Nos dias de hoje, um teria sido o cientista social, reformista e polêmico; o outro, o eficaz administrador, identificado e leal ao sistema.

Há trinta anos, a Biblioteca Nacional atendeu à necessidade imediata dos estudiosos com a primeira edição integral do Tesouro de João Daniel. Na ocasião, José Honório Rodrigues observou: "É pena que esta edição contenha deficiências inaceitáveis, tal como a falta do sumário da matéria, a falta de índice e uma introdução muito inferior ao livro, que revela não conhecê-lo, nem ter-se dado ao prazer de olhar, ainda que por cima, o original de impressão. As notas limitam-se à tradução de expressões latinas, mas nenhuma é histórico-geográfica e antropológica” (1979, p. 97). Dada a restrita circulação daquela primeira edição e o tempo que transcorreu, cumpre, agora, louvar a iniciativa da editora Contraponto e da Prefeitura de Belém por esta primeira edição de grande circulação e de condigna apresentação gráfica. Pena que poucas das deficiências apontadas por J.H.Rodrigues na primeira edição tenham sido sanadas nesta segunda. Que não tenha havido novo cotejo com o códice e os microfilmes da Biblioteca Nacional, ainda é admissível, embora devesse ser explicitado claramente, o que não ocorre na Nota do Editor. Mais grave é não ter sido acrescida ao texto uma única nota (e muitas eram necessárias) e

6 Antonil, André João (João Antonio Andreoni) - Cultura e opulência do Brasil por suas drogas e minas (1711). Introdução e vocabulário de A.P. Canabrava. São Paulo, Ed. Nacional, s.d. 
é frustrante a ausência de um índice analítico, que com os recursos hoje disponíveis teria sido perfeitamente factível. A Apresentação é muito superior à da primeira edição, mas contém falhas de revisão (v.g. as datas da morte de João Daniel, p.11, e do terremoto de Lisboa, p.16) e mesmo conceituais, como uma suposta aliança, em meados do século XVIII, entre "aristocracias rurais atraídas para a cidade" e a "burguesia" de Belém (p.18), ou "a economia igualitária das aldeias indígenas, espécie de socialismo missioneiro, que modificara o comunismo tribal" (ibid.). Isto relevado, não há como não saudar a tão esperada reedição de uma obra fundamental para a história da cultura brasileira.

P.S. Esta resenha já estava entregue para publicação, quando localizei, entre os documentos do Arquivo Histórico Ultramarino de Lisboa (Projeto Resgate, Capitania do Pará), os capítulos da Terceira Parte faltantes no códice da Biblioteca Nacional e nas duas edições integrais. Paleografados e anotados, estão publicados nas páginas 127 a 148 neste número da Revista do IEB. 